\title{
Use of Laparoscopy in the Treatment of Endometrial and Cervical Cancer - Results of a 2012 Germany-wide Survey
}

\section{Stellenwert der Laparoskopie in der Therapie der Endometrium- und Zervixkarzinome - Ergebnisse der AGE \& AGO Klinikumfrage 2012}

Authors

Affiliations
I. Juhasz-Böss ${ }^{1,4}$, P. Mallmann ${ }^{2,4}$, C. P. Möller ${ }^{3,5}$, E. F. Solomayer ${ }^{1,5}$

The affiliations are listed at the end of the article.

\section{Key words \\ - endometrial cancer \\ - cervical cancer \\ - surgical therapy \\ - laparoscopy \\ - endoscopy \\ - epidemiology \\ - gynaecology}

Schlüsselwörter

- Endometriumkarzinom

- Zervixkarzinom

- operative Therapie

- Laparoskopie

- Endoskopie

- Epidemiologie

- Frauenheilkunde

\section{received 30.4.2013 \\ revised $\quad 7.8 .2013$ \\ accepted $\quad 30.8 .2013$}

Bibliography

DOI http://dx.doi.org/

10.1055/s-0033-1350877

Geburtsh Frauenheilk 2013; 73:

911-917 @ Georg Thieme

Verlag KG Stuttgart • New York .

ISSN 0016-5751

\section{Correspondence}

PD Dr. Ingolf Juhasz-Böss

Universitätsklinikum

des Saarlandes

Klinik für Frauenheilkunde,

Geburtshilfe und

Reproduktionsmedizin

Kirrbergstraße 1

66424 Homburg/Saar

Ingolf.Juhasz-Boess@

uniklinikum-saarland.de

\section{Abstract}

\section{$\nabla$}

Introduction: Endoscopy has begun to play an increasingly important role in the surgical therapy of uterine cancers. To date, there is no data on the use of laparoscopy to treat endometrial cancer (EC) and cervical cancer (CC).

Method: A Germany-wide, anonymised survey was done of all gynaecological clinics/endoscopy clinics, using a standardised questionnaire.

Results: A total of 128 clinics responded: 16 university clinics (12.5\%), 30 hospitals offering maximum care (23.4\%), 66 general hospitals (51.5\%), 5 outpatient clinics $(3,9 \%), 4$ physicians in private practice affiliated to hospitals (3.1\%) and 7 hospitals (5.4\%) which did not indicate status. Laparoscopy was used in the treatment of $82 \%$ of all EC and $54 \%$ of CC. Surgery for EC was done completely laparoscopically in $58 \%$ of cases and with laparoscopic assistance using a vaginal approach in $32 \%$ of cases. If lymphadenectomy (LNE) was additionally performed, this was done abdominally in $42 \%$ of cases and laparoscopically in $53 \%$. Cervical cancer was treated by laparoscopic radical hysterectomy (HE) in $44 \%$ of cases and by radical HE using a vaginal approach in $14 \% .4 \%$ of hospitals reported the use of other endoscopic methods (e.g. DaVinci). While the majority of hospitals $(43.3 \%)$ treated more than $75 \%$ of EC patients using laparoscopy, in many clinics (38.3\%) less than $25 \%$ of CC patients were treated using endoscopy.

Discussion: Laparoscopy is used more often in EC surgery as compared to surgery for CC. However, there are still major differences between hospitals with regard to case numbers, the number of uterine cancers treated using endoscopic surgery, and the type of endoscopic surgery.

\section{Zusammenfassung \\ $\nabla$}

Einleitung: Die Endoskopie nimmt eine zunehmende Bedeutung in der operativen Therapie der Uteruskarzinome ein. Es gibt bis dato keine Daten, wie verbreitet der Einsatz der Laparoskopie (LSK) in der Therapie der Endometrium- (EC) und Zervixkarzinome (CC) ist.

Methode: Deutschlandweite anonymisierte Klinikumfrage unter allen gynäkologisch/endoskopisch operierenden Kliniken mittels standardisiertem Fragebogen.

Ergebnisse: 128 Klinikantworten: 16 Unikliniken (12,5\%), 30 Kliniken der Maximalversorgung (23,4\%), 66 Kliniken der Regelversorgung (51,5\%), 5 Tageskliniken (3,9\%), 4 Belegärzte $(3,1 \%)$ und 7 Kliniken (5,4\%) ohne Statusangabe. Die LSK kommt in $82 \%$ aller EC- und in 54\% aller CC zum Einsatz. EC werden in 58\% der Fälle komplett laparoskopisch und in 32\% der Fälle vaginal assistiert laparoskopisch operiert. Im Falle einer Lymphonodektomie (LNE) erfolgt diese in $42 \%$ der Fälle abdominal und in 53\% laparoskopisch. Beim CC erfolgt in $44 \%$ eine laparoskopische radikale Hysterektomie (HE) und in 14\% eine radikale HE in Kombination mit vaginalem Vorgehen. $4 \%$ der Kliniken geben an, weitere endoskopische Methoden (z.B. DaVinci) anzuwenden. Während die meisten Kliniken (43,3\%) mehr als 75\% der EC laparoskopisch behandeln, ist die Rate der endoskopisch operierten CC in den meisten Kliniken $(38,3 \%)$ unter $25 \%$.

Diskussion: EC werden häufiger als CC laparoskopisch operiert. Zwischen den Kliniken gibt es jedoch noch große Unterschiede bez. Fallzahl, der Anzahl der endoskopisch operierten Uteruskarzinome und der Art der endoskopischen OP. 


\section{Introduction}

Endometrial cancer and cervical cancer are the most common genital cancers in women. According to data published by the Robert Koch Institute in 2012, 11200 new cases with endometrial cancer and 4600 new cases with cervical cancer are diagnosed annually in Germany [1-4].

For both cancers, the therapy decision must also take account of the patient's general condition, the tumour stage, the risk factors and the patient's personal life plans and plans for a family.

In general, surgical therapy is the therapy of choice to treat earlystage primary endometrial and cervical cancer.

Laparoscopy has begun to play an increasingly important role in surgical therapy. Some working groups have already described their experiences with laparoscopy in the surgical oncological management of early-stage endometrial and cervical cancer. The main focus has been on laparoscopically assisted (radical) vaginal hysterectomy (LAVH) combined with laparoscopic lymphadenectomy (LNE) and radical or total laparoscopic hysterectomy (TLH) with bilateral adnexectomy and laparoscopic LNE.

Laparoscopy offers many advantages in gynaecological oncological surgery compared to laparotomy. Most authors have reported lower perioperative complication rates, less blood loss, fewer transfusions and shorter hospital stays as well as a better quality of life after laparoscopic hysterectomy compared to abdominal hysterectomy procedures to treat endometrial and cervical cancer [5-10].

One important aspect in the establishment of new procedures in surgical oncology is the oncological safety. Various study groups found no significant differences between laparoscopy and laparotomy for the treatment of uterine cancer with regard to oncological safety. Recurrence-free survival after laparoscopy to treat endometrial cancer was reported to be $90-100 \%$ and $92-95 \%$ after laparotomy $[6,11-21]$. Several randomised studies found no difference between laparoscopic and abdominal hysterectomy with regard to either total survival rates or recurrence-free survival rates $[14,20,21]$. Oncologically adequate LNE can also be achieved laparoscopically. The number of resected pelvic and paraaortal lymph nodes was found to be independent of the chosen method of surgical access, with laparoscopy comparable to laparotomy in this respect [22-25].

However, classic longitudinal laparotomy is still the standard procedure to treat uterine cancer. In recent years, however, endoscopy is increasingly being used in the treatment of uterine cancers - in line with the increasing rates of laparoscopic hysterectomies for benign uterine diseases. At present, however, there are no reliable data available on the incidence and prevalence of endoscopic procedures in gynaecological oncology. There has been no comprehensive statistical collection of data. The aim of our study was therefore to determine, for the first time and with the help of several professional associations, the total number or rates of clinics which offer endoscopic treatment for endometrial and cervical cancer. In addition, the study also aimed to investigate how often these procedures are actually carried out.

\section{Method}

$\nabla$

To determine the importance of laparoscopy in the treatment of uterine cancer, a Germany-wide survey of all gynaecological clinics carrying out endoscopic procedures was done in 2012. Together with the Study Group for Gynaecological Endoscopy (AGE) of the German Society for Gynaecology and Obstetrics (DGGG) and the Organ Commission "Uterus" of the German Study Group for Gynaecological Oncology (AGO), we compiled a two-page questionnaire. The questionnaire was sent to all members of AGE and of the Organ Commission "Uterus" of AGO by email. Members were requested to return the completed questionnaire by September 2012. The responses were anonymised, as was the evaluation.

The following parameters were investigated: information about the hospital (university hospital, hospital offering maximum care, general hospital or private ward) together with the number of cases with endometrial and cervical cancer treated annually in the hospital.

To evaluate the importance of laparoscopy in the treatment of primary endometrial cancer in the respective hospital, respondents were asked whether laparoscopy was used to treat primary endometrial cancer in the respective hospital (yes/no). If the answer was yes, respondents had a choice of ticking any one of the following boxes: only for the purpose of diagnosis or staging (with conversion to laparotomy at surgery with the extent of surgery depending on the cancer stage), predominantly for LAVH + $\mathrm{AE}$, predominantly for TLH $+\mathrm{AE}$, or other approach.

The percentage of endometrial cancers treated by laparoscopic surgery out of the total collective of EC patients in the respective hospital was also investigated ( $<25 \%, 25-50 \%, 50-75 \%$ or $>75 \%)$. Questions also included information on lymphadenectomy procedures. No details of the LNE (whether it was pelvic \pm paraaortal) were requested. If lymphadenectomy was indicated, the hospitals were requested to state whether LNE was done abdominally or laparoscopically or whether the patient was referred to another hospital for the procedure. If the patient was referred to another hospital for further treatment, hospitals were requested to state their reasons for the referral decision to a specific hospital (whether it had been a deliberate decision to select a particular hospital which would perform the completion surgery using laparoscopy or abdominally or whether this had not affected the decision).

To evaluate the importance of laparoscopy in the treatment of primary cervical cancer, respondents were asked whether laparoscopy was used to treat primary cervical cancer in their hospital (yes/no). If the answer was yes, respondents had a choice of the following options (multiple answers were possible): for the purposes of diagnosis and staging, for radical hysterectomy/"laparoscopic Wertheim procedure" using only a laparoscopic approach, for radical hysterectomy/"laparoscopic Wertheim procedure" using assisted laparoscopy and a vaginal approach, for radical vaginal trachelectomy with laparoscopic LNE, for radical laparoscopic trachelectomy with laparoscopic LNE, or other approach.

As was done for endometrial cancer, the rate of cervical cancers treated by laparoscopic surgery out of the total collective of CC patients treated in the respective hospital was also investigated (<25\%, $25-50 \%, 50-75 \%$ or $>75 \%$ ).

In addition, hospitals were requested to provide information on paraaortal LNE. If LNE was done for staging, respondents were requested to state whether this was done predominantly laparo- 


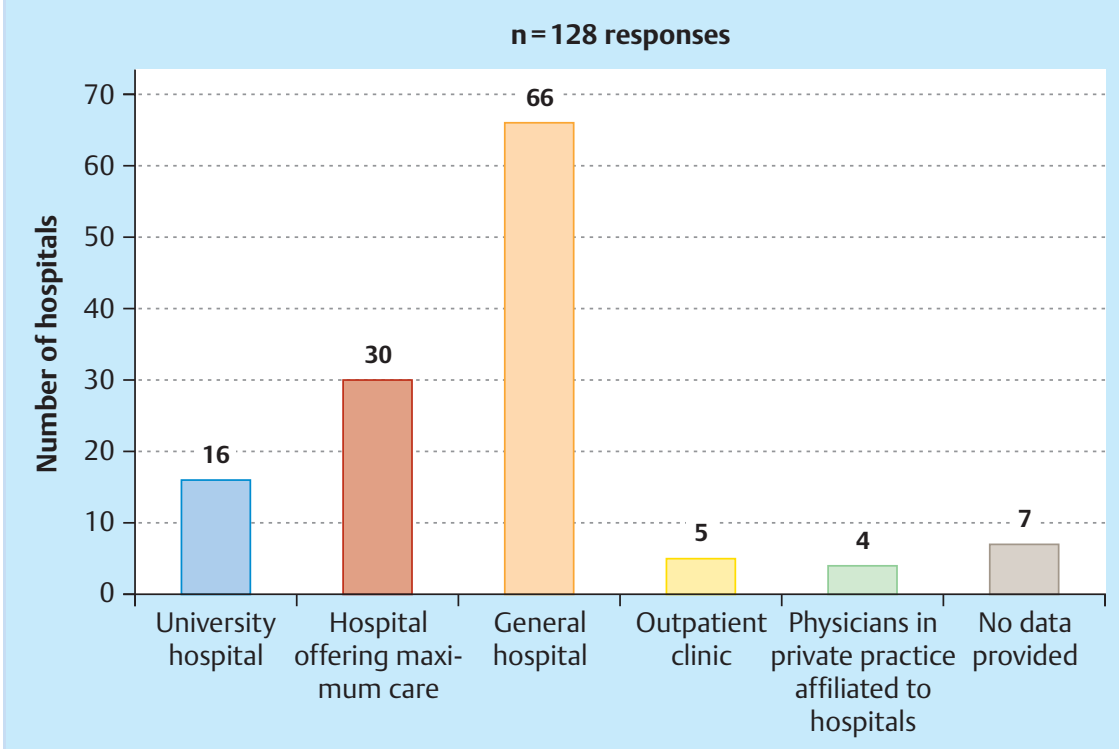

Fig. 1 Information on hospital size and status of all hospitals participating in the survey $(n=128)$.

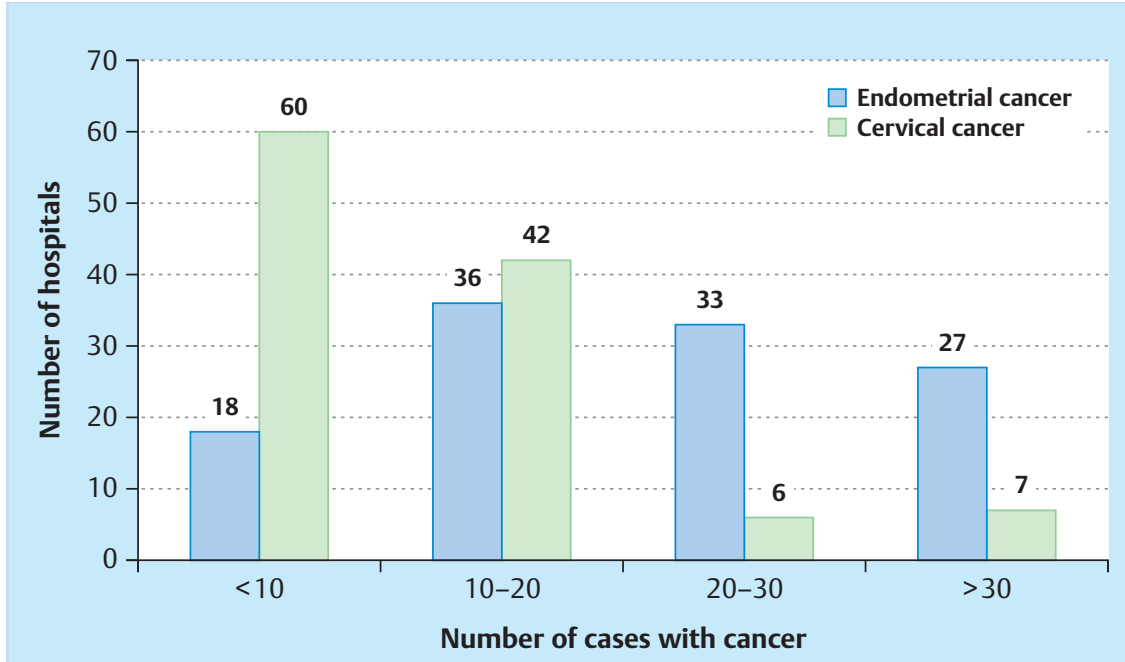

Fig. 2 Number of hospitals providing information on the number of cases with endometrial and cervical cancer treated annually in their facility.

scopically using a retroperitoneal, a transperitoneal or other approach.

\section{Results}

A total of $n=128$ hospitals were included in the survey; the questionnaire was sent to a total of 540 AGE members. This corresponds to a response rate of $23.7 \%$. The individual hospitals responded as follows: $12.5 \%(n=16)$ were university hospitals, $23.4 \%(n=30)$ were hospitals offering maximum care, $51.5 \%$ $(n=66)$ were general hospitals, 3.9\% $(n=5)$ were outpatient clinics, $3.1 \%(n=4)$ were physicians in private practice affiliated to hospitals, and $5.4 \%(n=7)$ of hospitals did not provide information on the size and status of their facility ( Fig. 1).

The data for the number of cases with primary endometrial cancer treated annually in the respective hospital was as follows: 18 hospitals (15.7\%) treated fewer than 10 cases with endometrial cancer, 36 hospitals (31.5\%) treated between 10 and 20 cases, 33 hospitals (28.9\%) between 20 and 30, and 27 hospitals
(23.7\%) treated more than 30 cases with primary endometrial cancer each year ( Fig. 2). As regards the number of cases with primary cervical cancer, 60 hospitals $(52.1 \%)$ treated fewer than 10 cases per year, 42 hospitals (36.5\%) treated between 10 and 20 cases, 6 hospitals (5.2\%) treated between 20 and 30 cases, and 7 hospitals (6\%) treated more than 30 cases with primary cervical cancer each year ( $\bullet$ Fig. 2 ).

\section{Endometrial cancer}

Laparoscopy was used in the surgical treatment of endometrial cancer in $82 \%(n=105)$ of responding hospitals ( Fig. 3 ). In $58 \%$ of cases, laparoscopy was used for total laparoscopic hysterectomy and bilateral adnexectomy, in $32 \%$ of cases for laparoscopically assisted vaginal hysterectomy (and bilateral adnexectomy), in $4 \%$ of cases for staging, and in $6 \%$ of cases other endoscopic methods, for example "DaVinci", were used ( Fig. 4).

The rates of patients with endometrial cancer treated endoscopically in the respective hospital are shown in Fig. 5. Twentyeight hospitals (26\%) treated less than $25 \%$ of endometrial cancers using laparoscopy, 17 hospitals (15.7\%) treated between 


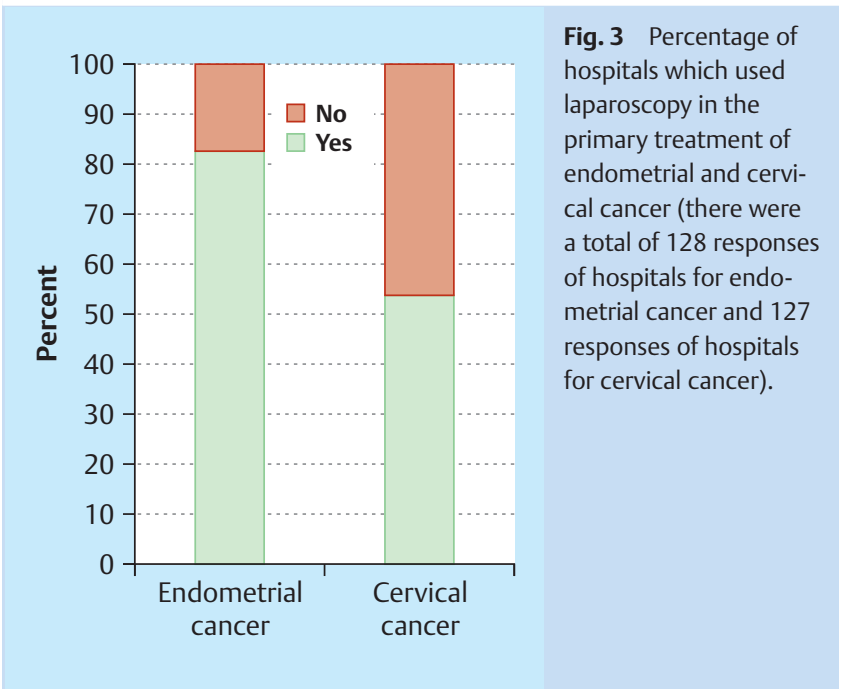

$25 \%$ and $50 \%$ of cases using laparoscopy, 17 hospitals (15.7\%) treated between $50 \%$ and $75 \%$ of cases using laparoscopy, and 46 hospitals (43.3\%) treated more than $75 \%$ of cases with endometrial cancer using laparoscopy ( $\bullet$ Fig. 5 ).

If lymphadenectomy was necessary, the procedure was done abdominally in $42 \%$ of hospitals and laparoscopically in $53 \%$ of hospitals. $5 \%$ of hospitals referred the patients to other hospitals. If the patient was referred to another hospital for lymphadenectomy, in $55 \%$ of cases $(n=28)$ the referral was to a hospital in which completion surgery was done using laparoscopy and in 6\% of cases $(n=3)$ to a hospital where surgery was done using an abdominal approach. In $39 \%$ of cases $(n=20)$ the referring hospital had no preference with regard to the type of further treatment.

\section{Cervical cancer}

Laparoscopy was used to treat primary cervical cancer in $53.1 \%$ of hospitals ( $n=68$ ) ( Fig. 3). Of these, $48.5 \%$ of hospitals $(n=33)$ used laparoscopy for diagnosis, $73.5 \%$ of hospitals $(n=50)$ for radical hysterectomy using a completely endoscopic approach, $20.5 \%$ of hospitals for radical hysterectomy using a vaginal approach, $19.1 \%$ of hospitals for radical vaginal trachelectomy combined with laparoscopic lymphadenectomy, one hospi-

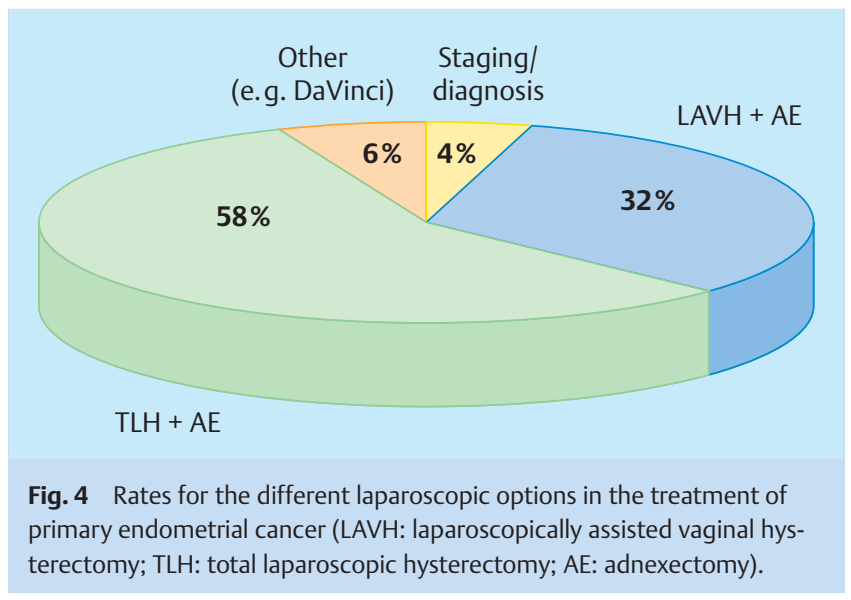

tal (1.4\%) for radical laparoscopic trachelectomy with laparoscopic lymphadenectomy, and $7.3 \%$ of hospitals $(n=5)$ used other endoscopic methods (e.g. DaVinci, TMMR). Multiple answers were possible ( $\bullet$ Fig. $\mathbf{6}$ ).

The percentage of patients treated surgically using laparoscopy out of the total collective of patients treated in the respective hospital was less than $25 \%$ in 28 hospitals (38.3\%), between $25 \%$ and $50 \%$ in 15 hospitals (20.5\%), between $50 \%$ and $75 \%$ in 16 hospitals (21.9\%), and more than $75 \%$ in 14 hospitals (19.1\%) (๑ Fig. 5).

For laparoscopic paraaortal lymphadenectomy, 79\% of hospitals $(n=50)$ used a transperitoneal, $5 \%$ of hospitals used a retroperitoneal $(n=3)$ and $16 \%$ of hospitals $(n=10)$ another approach.

\section{Discussion}

Endoscopy is becoming increasingly important in gynaecology. The numbers of patients treated with endoscopic surgery in gynaecological oncology are increasing. To date, however, it is not clear how widespread the use of endoscopy for the treatment of

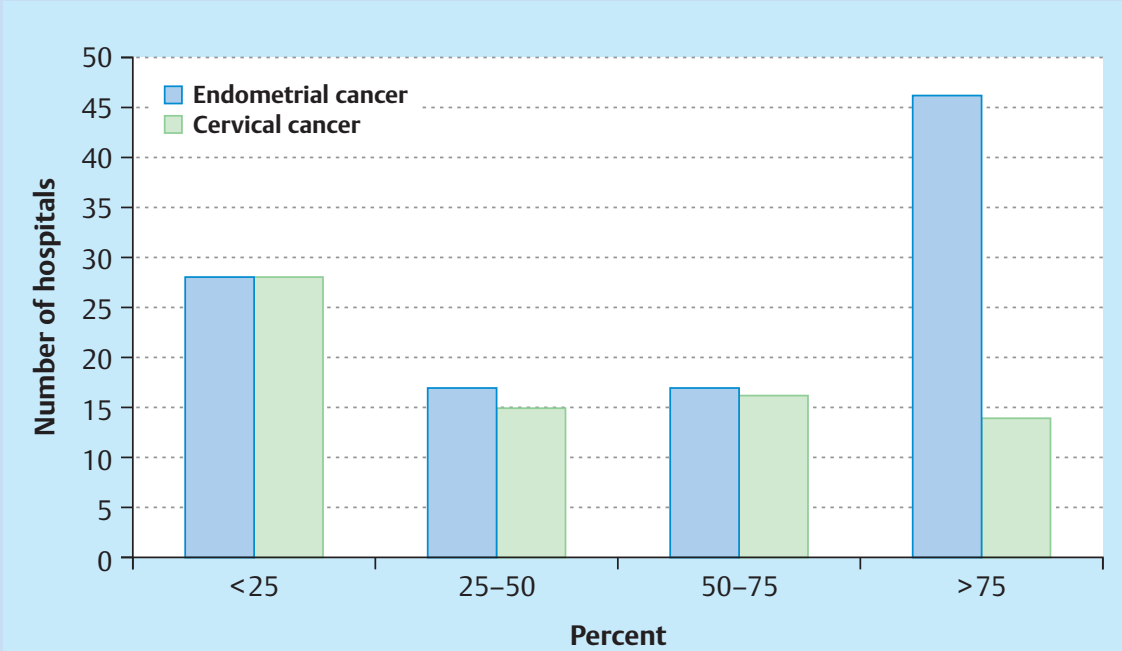

Fig. 5 Number of hospitals providing information on the percentages of patients with endometrial or cervical cancer treated surgically using laparoscopy out of the total collective of patients in the respective hospital. Respondents had a choice of ticking the boxes "less than $25 \%$ ", "25-50\%", " $50-75 \%$ " or "more than $75 \%$ " for the respective cancer type treated using laparoscopy in their respective hospital. Data were collected separately for endometrial and cervical cancer. 


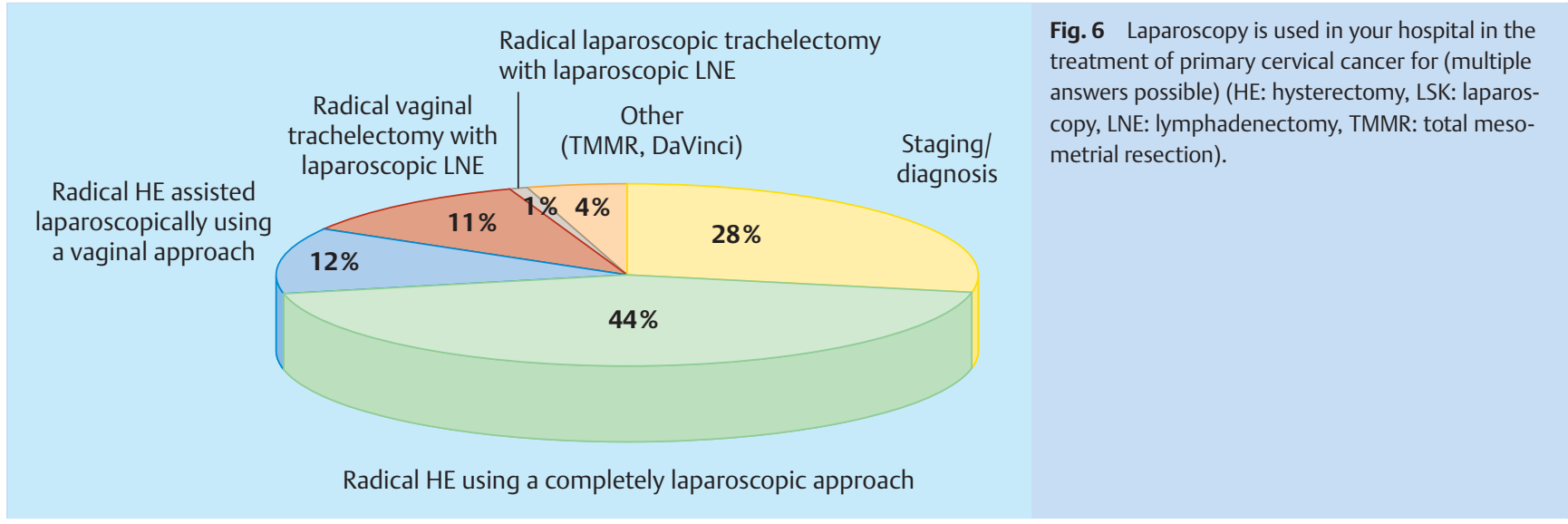

uterine cancer is. This survey therefore aimed to investigate the incidence and prevalence of endoscopic surgery in the treatment of endometrial and cervical cancer in Germany by means of an anonymised survey. It should also be noted that this is the first time this survey was carried out, and it was done in cooperation with two professional associations, the Study Group for Gynaecological Endoscopy (AGE) and the Organ Commission "Uterus" of the German Study Group for Gynaecological Oncology (AGO). A total of 128 hospitals responded and sent back the completed questionnaire. The exact number of hospitals carrying out gynaecological oncology surgery in Germany is not clear, but it is safe to assume that there are several hundred. A response rate of 128 completed questionnaires for a voluntary and unremunerated survey must be considered good, given that, in our experience, the response rates for other comparable surveys undertaken in Germany were not much higher (e.g. the rate for the cervical cancer survey by Mangler et al. was 34\% [26]). The calculated response rate of $23.7 \%$ may even be slightly higher, as we did not send out the letters to 560 hospitals but to AGE members, and the stipulation was that only one questionnaire should be returned (anonymously) per hospital. Given that in some hospitals there may be several AGE members, it can be assumed that the percentage of responses was higher.

The distribution of responses shows that university hospitals (approx. 12.5\% of all participating hospitals) were slightly overrepresented. Almost 50\% of gynaecological university hospitals participated in the survey. The majority of responding hospitals were general hospitals (52\%), followed by hospitals offering maximum care (23\%). Happily, a number of outpatient clinics (4\%) and private physicians affiliated to hospitals (3\%) also participated in the survey. Overall, it can be assumed that our collective represents a representative distribution of hospitals carrying out gynaecological oncology surgery in Germany.

It should again be emphasised that currently there is almost no data available on the use of endoscopic procedures in gynaecological oncology. There is no reliable survey on this issue. The information can only be collected on a voluntary basis, so that it is not possible to exclude bias. But there is almost no better method of obtaining data to answer these questions. We have to assume that hospitals which do not use laparoscopy in gynaecological oncology procedures would be less likely to answer the questionnaire. And of course, not all centres or hospitals which use laparoscopy in gynaecological oncology responded to our questionnaire. The percentage of hospitals using endoscopy is likely to be higher in our collective than the actually existing rate for Germany.

The number of cases with cervical cancer was much lower than the number of patients with endometrial cancer. While only $16 \%$ of hospitals treated fewer than 10 cases with primary endometrial cancer annually, 52\% of hospitals treated fewer than 10 cases with primary cervical cancer. Only $11 \%$ of hospitals treated more than 20 cases with primary cervical cancer, while $53 \%$ of all hospitals treated more than 20 cases with endometrial cancer annually. These figures confirm the results of Mangler et al. According to their study published in 2013 , only $9 \%$ of all gynaecology clinics in Germany treat more than 25 cases with cervical cancer annually [26]. The result is that the level of expertise for the treatment of cervical cancer is significantly lower than for endometrial cancer. The figure is as expected and mirrors the distribution of primary cervical cancer compared to endometrial cancer.

According to our survey, in 53\% of cases laparoscopy was used in the treatment of cervical cancer. However, this figure also includes diagnostic and staging laparoscopies in addition to laparoscopic surgery, and $28 \%$ of hospitals reported that they used laparoscopy "only" for diagnosis or staging. This qualifier results in a reduced "adjusted" rate of hospitals which explicitly carry out endoscopic radical hysterectomy procedures (irrespective of whether the preferred procedure is LARVH, TLRH, "robotics" etc.). Based on the results of their survey, Mangler et al. showed that $71 \%$ of all gynaecological clinics in Germany resected cervical cancer using abdominal radical hysterectomy. This discrepancy once again demonstrates, as discussed above, that the percentage of hospitals carrying out endoscopic surgery in our collective was probably higher than the overall figure for all of Germany. Fortunately, the treatment of endometrial cancer is often carried out using endoscopy ( $82 \%$ ). However, only $58 \%$ of surgical procedures for EC were carried out completely endoscopically. A further $32 \%$ of cases used a vaginal approach under endoscopic control. Our data shows the different procedures used for one and the same surgical indication. The use of endoscopy to treat endometrial cancer would be preferable as it offers the only means of achieving adequate intraoperative staging (peritoneal cancer, tumour seeding, lymph node assessment, etc.) without the morbidity associated with longitudinal laparotomy. Even if lymphadenectomy is not required in many cases due to the tumour stage, endoscopy is an important step of oncological therapy. Laparotomy is generally not required; it is only mandated for the treatment of advanced stage cancer [27]. Numerous studies have 
demonstrated that laparoscopy is superior or at least equal to laparotomy [17,20,28-34].

It must noted critically at this point that, while data is available on the short-term and medium-term safety of endoscopic oncology procedures for both cervical and endometrial cancer, data on long-term safety is still lacking. Endoscopic procedures therefore still need to be critically discussed and patients must be informed about this issue. And it must also be noted at this point that, in addition to the benefits of laparoscopy, the procedure also has a number of drawbacks which include longer operating times and higher levels of technical expertise. Unfortunately, there are no adequate figures which would offer a cost-benefit analysis of the use of laparoscopy in the treatment of uterine cancer in Germany. Overall, cost-benefit evaluations have demonstrated that laparoscopy is an expensive procedure. The level of expertise required is, as was already mentioned, much higher than for open procedures. Thus, despite the probable increase in the use of laparoscopy in surgical oncology, laparoscopy is likely to remain the preserve of hospitals with higher levels of surgical expertise.

Nevertheless, laparoscopy can be expected to play an increasingly important role in future. It is probable that it will be used in more and more hospitals, and we can assume that gynaecological oncology procedures will increasingly move away from laparotomy to laparoscopic surgery. These data therefore offer a topical overview of the role of laparoscopy in the surgical treatment of endometrial and cervical cancer. But it should be pointed out that the survey was carried out in hospitals with a special focus on endoscopy and/or uterine cancer, and thus the representative value of these results regarding the general availability of endoscopy in Germany is limited. Nevertheless, these results represent the most meaningful data to date on the importance of laparoscopy in the treatment of uterine cancer.

\section{Conflict of Interest}

$\nabla$

None.

\section{Affiliations}

1 Klinik für Frauenheilkunde, Geburtshilfe und Reproduktionsmedizin, Universitätsklinikum des Saarlandes, Homburg/Saar

2 Frauenklinik, Uniklinik Köln, Cologne

${ }^{3}$ Tagesklinik Altonaer Straße, Hamburg

${ }^{4}$ Kommission Uterus der AGO - Arbeitsgemeinschaft Gynäkologische Onkologie e. V.

${ }^{5}$ AGE - Arbeitsgemeinschaft Gynäkologische Endoskopie e.V. der Deutschen Gesellschaft für Gynäkologie und Geburtshilfe e. V. (DGGG)

\section{References}

1 AGO; DKG; DGGG. Diagnostik und Therapie des Endometriumkarzinoms. Interdisziplinäre S2-Leitlinie, AWMF 032/034. www.awmf.de

2 AGO; DKG; DGGG. Diagnostik und Therapie des Zervixkarzinoms. Interdisziplinäre S2 k-Leitlinie, AWMF 032/033. www.awmf.de

3 Robert Koch-Institut; die Gesellschaft der epidemiologischen Krebsregister in Deutschland e.V., Hrsg. Krebs in Deutschland 2007/2008. 8. Ausgabe. Berlin: 2012

4 Waldmann A, Eisemann N, Katalinic A. Epidemiology of malignant cervical, corpus uteri and ovarian tumours - current data and epidemiological trends. Geburtsh Frauenheilk 2013; 73: 123-129

5 Eltabbakh GH. Analysis of survival after laparoscopy in women with endometrial carcinoma. Cancer 2002; 95: 1894-1901

6 Magrina JF, Mutone NF, Weaver AL et al. Laparoscopic lymphadenectomy and vaginal or laparoscopic hysterectomy with bilateral salpingooophorectomy for endometrial cancer: morbidity and survival. Am J Obstet Gynecol 1999; 181: 376-381
7 Magrina JF, Weaver AL. Laparoscopic treatment of endometrial cancer: five-year recurrence and survival rates. Eur J Gynaecol Oncol 2004; 25 : 439-441

8 Zullo F, Palomba S, Russo T et al. A prospective randomized comparison between laparoscopic and laparotomic approaches in women with early stage endometrial cancer: a focus on the quality of life. Am J Obstet Gynecol 2005; 193: 1344-1352

9 Spirtos NM, Schlaerth JB, Gross GM et al. Cost and quality-of-life analyses of surgery for early endometrial cancer: laparotomy versus laparoscopy. Am J Obstet Gynecol 1996; 174: 1795-1799; discussion 1799-1800

10 Solomayer EF, Becker S. Neue Entwicklungen der Zervixkarzinom-Chirurgie - der laparoskopische Wertheim. Geburtsh Frauenheilk 2007; 12: $1375-1377$

11 Hidlebaugh DA, Orr RK. Staging endometrioid adenocarcinoma. Clinica and financial comparison of laparoscopic and traditional approaches. J Reprod Med 1997; 42: 482-488

12 Gemignani ML, Curtin JP, Zelmanovich J et al. Laparoscopic-assisted vaginal hysterectomy for endometrial cancer: clinical outcomes and hospital charges. Gynecol Oncol 1999; 73: 5-11

13 Scribner jr. DR, Walker JL, Johnson GA et al. Surgical management of early-stage endometrial cancer in the elderly: is laparoscopy feasible? Gynecol Oncol 2001; 83: 563-568

14 Malur S, Possover M, Michels W et al. Laparoscopic-assisted vaginal versus abdominal surgery in patients with endometrial cancer - a prospective randomized trial. Gynecol Oncol 2001; 80: 239-244

15 Holub Z, Jabor A, Bartos P et al. Laparoscopic surgery for endometrial cancer: long-term results of a multicentric study. Eur J Gynaecol Oncol 2002; 23: 305-310

16 Manolitsas TP, McCartney AJ. Total laparoscopic hysterectomy in the management of endometrial carcinoma. J Am Assoc Gynecol Laparosc 2002; 9: 54-62

17 Fram KM. Laparoscopically assisted vaginal hysterectomy versus abdominal hysterectomy in stage I endometrial cancer. Int J Gynecol Cancer 2002; 12: 57-61

18 Eltabbakh GH, Shamonki MI, Moody JM et al. Laparoscopy as the primary modality for the treatment of women with endometrial carcinoma. Cancer 2001; 91: 378-387

19 Obermair A, Manolitsas TP, Leung Y et al. Total laparoscopic hysterectomy for endometrial cancer: patterns of recurrence and survival. Gynecol Oncol 2004; 92: 789-793

20 Tozzi R, Malur S, Koehler C et al. Laparoscopy versus laparotomy in endometrial cancer: first analysis of survival of a randomized prospective study. J Minim Invasive Gynecol 2005; 12: 130-136

21 Juhasz-Böss I, Haggag H, Baum S et al. Laparoscopic and laparotomic approaches for endometrial cancer treatment: a comprehensive review. Arch Gynecol Obstet 2012; 286: 167-172

22 Zullo F, Falbo A, Palomba S. Safety of laparoscopy vs. laparotomy in the surgical staging of endometrial cancer: a systematic review and metaanalysis of randomized controlled trials. Am J Obstet Gynecol 2012; 207: 94-100

23 Ju W, Myung SK, Kim Y et al. Comparison of laparoscopy and laparotomy for management of endometrial carcinoma: a meta-analysis. Int J Gynecol Cancer 2009; 19: 400-406

24 Palomba S, Falbo A, Russo T et al. Updating of a recent meta-analysis of randomized controlled trials to assess the safety and the efficacy of the laparoscopic surgery for treating early stage endometrial cancer. Gynecol Oncol 2009; 114: 135-136

25 Juhasz-Boess I. Oncological safety of laparoscopy in endometrium carcinoma. Onkologe 2012; 18: 714-717

26 Mangler M, Zech N, Schneider A et al. Aspects of therapy for cervical cancer in Germany 2012 - results from a survey of german gynaecological hospitals. Geburtsh Frauenheilk 2013; 73: 1-12

27 Juhasz-Böss I, Fehm T, Becker S et al. Endometrial cancer: comparison of patients with synchronous primary carcinoma of the endometrium and ovary vs. endometrial carcinoma with ovarian metastases. Geburtsh Frauenheilk 2012; 72: 721-726

28 Walker JL, Piedmonte MR, Spirtos NM et al. Recurrence and surviva after random assignment to laparoscopy versus laparotomy for comprehensive surgical staging of uterine cancer: Gynecologic Oncology Group LAP2 Study. J Clin Oncol 2012; 30: 695-700

29 Walker JL, Piedmonte MR, Spirtos NM et al. Laparoscopy compared with laparotomy for comprehensive surgical staging of uterine cancer: Gynecologic Oncology Group Study LAP2. J Clin Oncol 2009; 27: 5331-5336 
30 Zorlu CG, Simsek T, Ari ES. Laparoscopy or laparotomy for the management of endometrial cancer. JSLS 2005; 9: 442-446

31 Malzoni M, Tinelli R, Cosentino F et al. Total laparoscopic hysterectomy versus abdominal hysterectomy with lymphadenectomy for earlystage endometrial cancer: a prospective randomized study. Gynecol Oncol 2009; 112: 126-133

32 Zullo F, Palomba S, Falbo A et al. Laparoscopic surgery vs laparotomy for early stage endometrial cancer: long-term data of a randomized controlled trial. Am J Obstet Gynecol 2009; 200: 296.e1-296.e9
33 Janda M, Gebski V, Brand A et al. Quality of life after total laparoscopic hysterectomy versus total abdominal hysterectomy for stage I endometrial cancer (LACE): a randomised trial. Lancet Oncol 2010; 11: 772-780

34 Mourits MJ, Bijen CB, Arts HJ et al. Safety of laparoscopy versus laparotomy in early-stage endometrial cancer: a randomised trial. Lancet Oncol 2010; 11: 763-771

Deutschsprachige Zusatzinformationen online abrufbar unter: www.thieme-connect.de/ejournals/toc/gebfra. 